\title{
Accomplishing Modernity: Dewey's Inquiry, Childhood and Philosophy
}

\section{Stefano Oliverio}

\section{Abstract}

Against the backdrop of two remarks by Martha Nussbaum on Dewey and Socratic education (which can be connected with a statement by Matthew Lipman about his going beyond Dewey in a Deweyan way), the paper explores what seems to be a sort of ambivalence in Dewey's educational device. On the one hand, by recognizing children as inquirers and the attitude of childhood as "very near to the attitude of the scientific mind", Dewey infringes on the modern (Cartesian-Kantian) pattern which separates childhood knowledge and reflective thinking. Such a move represents a more radical Copernican revolution in comparison with the Kantian one and a way of accomplishing modernity in that, by reformulating the relationships between experience and thinking, it allows Dewey to recognize the child as an epistemic agent and at the same time as a pivot of the educational process. On the other hand, despite this valorisation of children's epistemic powers and despite his emphasis on philosophy as a general theory of education, Dewey failed to mobilise philosophical inquiry as a way of educating children for thinking. In the final part of the paper some possible explanations are advanced about why in Dewey philosophy does not take on the educational role that it will have in Lipman.

In her recent much-debated manifesto for Socratic education, Martha Nussbaum (2010) makes two statements seemingly dissonant with each other: on the one hand, she recognizes in Dewey "a thinker who brought Socrates into virtually every American classroom" (p. 64); on the other hand, she points out that "Dewey, 
however, never addressed systematically the question of how Socratic critical reasoning might be taught to children of various ages" (p. 73). The latter remark works as a sort of springboard to the introduction of Matthew Lipman's curriculum as a "source of practical guidance" for teachers "who want to teach Socratically" (p. 73).

We could rephrase such a double position in the evaluation of Dewey's contribution to Socratic education in this way: although Dewey, by appealing to students as "active, curious, critical" (Nussbaum, 2010, p. 65) and not as a mere target of the indoctrinating transmission of contents, revived the Socratic legacy in American classrooms, it was Matthew Lipman who really devised an effective procedure of Socratic teaching. And he did it exactly by valorizing that "subject-matter," philosophy, that was not at the center of Dewey's educational proposal. Through such a hermeneutical bending, Nussbaum's double remark could be profitably connected to what Lipman averred in an interview:

I took from Dewey the idea that a classroom session must begin with something that stimulates the interest of the children and then leads them to reflect on the meaning of their experience ... What Dewey didn't realise was that a discipline such as philosophy, which he had right under his nose, so to speak, could be used for this purpose. In this sense, Philosophy for Children is a Deweyan way of going beyond Dewey. (Striano, 2002, p. 63)

From this perspective, the question about the unaccomplished pedagogical "Socratism" in Dewey becomes co-extensive with that about the "Deweyan ulteriority" of Lipman, his going beyond Dewey in a Deweyan way. In a previous paper (Oliverio, 2011), I attempted to show how Lipman implicitly capitalizes on the scientific origin of the notion of the community of inquiry (in Peirce and Dewey) to avoid some traps of the philosophical tradition (first of all the view of thinking as a solitary occupation [Arendt, 1982]). But Lipman's debt to the scientific matrix of the Deweyan (and, more broadly, pragmatist) legacy is only a part of the story (although an important and often neglected one): the other side of the coin is exactly Lipman's (Socratic) "ulteriority" in reference to Dewey, the idea of mobilizing philosophy while sticking to the Deweyan approach.

In order to better spell out such an ulteriority we can state that Lipman believes, with Dewey, that "children will think freely and creatively about whatever problems concern them if only the conditions of their educational lives are properly arranged. ... The teacher and the curriculum must instigate and promote the child's native tendency to inquiry" (Lipman \& Sharp, 1994, p. 13). At the same time, though, Lipman mistrusts the bending which "the commitment to the method of inquiry” (p. 4) acquired in Dewey's followers:

That commitment was an enormous advance over the traditional conception of education, but Dewey's constant encouragement of the child's engagement in independent reflection about all dimensions of experience was not maintained by his followers. Dewey's superb grasp of the possibilities of education became limited solely to the inquiry method, which was seen 
as a rational technique for problem-solving to be applied to the manageable areas of human life. This almost by definition excluded philosophical concerns, and metaphysical and epistemological issues were ignored. The formulation and resolution of problematic situations was proposed as the only valid paradigm for exploring and understanding the world. (pp. 4-5)

It is certain here that Lipman does not burden Dewey with the responsibility for such a narrowing of the scope of the idea of inquiry. By referring to the aforementioned interview we can surmise, however, that he considered his own main merit that of having integrated philosophy into the Deweyan framework by devising a way of developing a philosophical inquiry in the classroom. Dewey, on the other hand, did not insist explicitly on the need to bring philosophy into the (primary) school nor did he stress adequately the wealth of educational opportunities embedded within the philosophical tradition. Lipman could state that he went beyond Dewey in a Deweyan way because Philosophy for Children, while appealing to the Deweyan model of inquiry in education,

is an attempt to reconstruct and present the history of philosophy in such a way that children can appropriate it for themselves so as to reason well in a self-correcting manner. For children to develop the ability to think well for themselves about matters of importance, what is required is an educational enterprise consisting of philosophical dialogue, within the context of a classroom community of inquiry.... Philosophy for Children is a method of dialogical reflection coupled with twenty-five hundred years of various views and systems of thought regarding the nature of the universe, the characteristics of the good life, and the cultivation of wisdom. (Sharp \& Reed, 1992, p. xiii)

The question that should be raised is why Dewey failed to recognize the educational value of philosophy as a practice to be carried out in the classroom community of inquiry while at the same time considering philosophy as the general theory of education (MW 7: 303; MW 9: 338). In order to avoid misunderstandings, the sense of the question needs to be specified. It cannot be gainsaid that in Dewey there is an intimate connection between philosophy and education. Indeed, he explicitly links the Socratic turn in philosophy to the interest in education: "After a period in Greece in which inquiry was devoted to inquiry into nature, with man subordinated, philosophy turned in Athens to the study of Man. Socrates, as the saying goes, brought philosophy down from the heavens to earth. It is often forgotten that this change coincided with an interest in education; it was indeed an outgrowth of interest in the possibilities of education in its large sense" (LW 5: 289).

What is worth considering here, in the light of the major Lipmanian innovation, is that philosophy as a discipline and the history of philosophy as a repertoire of theories and strategies were not mobilized by Dewey to attain educational goals. As highlighted by Sharp and Reed in the aforementioned passage, it is the history of philosophy which is to be deployed in the Philosophy for Children (P4C) approach, 
through a work of "translation" which makes it effective for the reorganization of children's experience. If it is, therefore, legitimate to argue that philosophy is not alien to the Deweyan educational proposal, as it is co-extensive with education, such a statement risks missing the target: what is to be asked is why philosophy as a discipline was not appealed to within the Deweyan framework. And the question concerns both the content level, so to speak, that is the history of philosophy as a collection of themes, theories, and important questions, which broadens children's ability to have meaningful experiences, and the level of the development of forms of reflective thinking. On this latter point, it is to be asked why Dewey did not thematize the value of the philosophical inquiry for the cultivation of habits of reflective thinking.

Many answers to this question can be provided, but what I want to investigate here is how such a scotoma in Dewey is related to and rooted in his idea of the child as an inquirer and in his view of philosophy.

The argument, therefore, will be articulated in two steps: first, I will attempt to pinpoint the revolutionary contribution of Dewey to the recognition of the epistemic rights of childhood (it is the reason why we can credit Dewey with introducing Socrates into all classrooms and why Lipman considered himself a Deweyan); second, I will indicate a possible explication for why Dewey did not extend such a recognition to the valorizing of the "philosophical talent" of children.

In the preface to the first edition of How We Think, Dewey makes a remark that, anodyne, incidental, and just preliminary as it may appear, is in reality a revolutionary turning point in the epistemology and pedagogy of modernity: "This scientific attitude of mind might, conceivably, be quite irrelevant to teaching children and youth. But this book also represents the conviction that such is not the case; that the native and unspoiled attitude of childhood, marked by ardent curiosity, fertile imagination, and love of experimental inquiry, is near, very near, to the attitude of the scientific mind" (LW 8: 109).

Such a solidarity between childhood and the scientific mind infringes on one of the hidden axioms of the modern view of thinking and rationality from Descartes to Kant. Indeed, in one and the same move Cartesian modernity codifies a specific idea of science and the expulsion of childhood from the domain of knowledge. The two main phenomena at the dawning of modernity-the invention of childhood and the birth of science-can be read as two sides of the same coin (Kennedy, 1989): on the one hand, thanks primarily to the work of Descartes, science is conceived as an enterprise inspired by mechanicism and, therefore, engaged in smoking out all qualitative elements in knowledge and in sacrificing them on the altar of scientific (quantitative and mathematical) procedures. There is-in the Cartesian idea of science-an unbounded will of disenchantment of which the evil genius is a prosopopeia. The evil genius is not something that subjectivity is subjected to but it is a fiction which subjectivity, in the course of its self-making, inflicts on itself in order to detect and erase all the vestiges of impure, imperfect, and uncertain knowledge. If the evil genius is so strategic in Descartes it is because 
through it (which is the proto-move of subjectivity) subjectivity comes to itself in its own translucid purity, by dismissing childhood knowledge. Indeed, to Descartes, the source of any wrong knowledge is childhood because at that age knowledge is only sensory, and, therefore, animistic, anthropomorphic, qualitative (Descartes, 1908, p. 5, pp. 35-36). The ideal cogito (that is, subjectivity as spotless evidence which founds and supports the building of science) should be "adamitic": if human beings were like Adam and Eve, who were not "born as infants, but created as adults" (Descartes, 1908, p. 100), the meditational path to cogito would be useless and the fiction of the evil genius superfluous. But, since human beings were born as children, the cogito is a task ahead and science is a target which can be attained only by dismissing childhood knowledge.

But this way of telling the story is one-sided: it presupposes that an age called childhood already existed as such and that the problem of Descartes, in his foundational effort, was to overcome it. It should be said, instead, that the modernCartesian need for a buffered self (Taylor, 2007), for a subjectivity shielded from the lapses into qualitative and naïve knowledge, urged modernity to invent a condition (childhood) that operates as a receptacle for all kinds of knowledge which are inadequate from the standpoint of science. Before the affirmation of science such nonscientific knowledge was legitimate and did not represent a factor of minority: it was just one of the ways of human intercourse with the world. But the mathematical project of modernity demanded the expulsion of qualitative and anthropomorphic knowledge and an age was invented-childhood-where such knowledge could have a citizenship, but only because childhood is a transient phase of human life, whereas the full flourishing of humanity, its maturity (the Kantian Mündigkeit), consists in abandoning this condition and in the self-installing of subjectivity in its capacity of rationality, that is, of being a citizen in the realm of scientific thinking.

Coming of age and becoming able of science are, then, one and the same thing (Piaget is still entirely within this tradition). So in the Cartesian-modern pattern, childhood and science are on opposite epistemic sides: in order that science obtains, childhood has to be suppressed. The construction of science is not the reconstruction of childhood experience but its negation. In comparison to such a perspective, the Dewey propositions from which we started represent a revolutionary stance: while in Cartesian modernity there is an antithesis between science and childhood, in Dewey a solidarity obtains.

Before investigating Dewey's revolutionary move we have to dwell on a possible objection: the story of the gulf between childhood and science has been told thus far by recurring to the "rationalist" strand of the modern philosophical tradition: what about the "empiricist" strand and its more empirical kind of science? I will tackle such an issue by referring to the adamitic metaphor. In Descartes, as I have attempted to show, there is the dream of a sort of an adamitic condition that preserves the cogito from the lapses connected with childhood knowledge, which is sensory and therefore con-fused (that is, branded by the mingling of soul/mind and 
body). Adam appears in Hume in a key-passage ${ }^{1}$ which is worth mentioning. In the Abstract of the Treatise of Human Nature, we read that, given the shock of two balls,

[w] ere a man, such as Adam, created in the full vigour of understanding, without experience, he would never be able to infer motion in the second ball from the motion and impulse of the first. It is not anything that reason sees in the cause which makes us infer the effect. Such an inference, were it possible, would amount to a demonstration, as being founded merely on the comparison of ideas. But no inference from cause to effect amounts to a demonstration, of which there is this evident proof.... It would have been necessary, therefore, for Adam (if he was not inspired) to have had experience of the effect which followed upon the impulse of these two balls. He must have seen, in several instances, that when the one ball struck upon the other, the second always acquired motion. If he had seen a sufficient number of instances of this kind, whenever he saw the one ball moving towards the other, he would always conclude without hesitation that the second would acquire motion. His understanding would anticipate his sight and form a conclusion suitable to his past experience. (Hume, 1740)

Adam is "the perfect Cartesian," and through such an example Hume shows that "knowledge of the world is not possible on Cartesian grounds" (Robison, 2006, p. 30). The refusal of any adamitic condition (and of the related science) seems to clear the ground for the recognition of childhood knowledge of the world. Science, from such an empiricist perspective, and childhood would not be on opposite sides, but would exist at most in an incremental sequence. Is therefore the move accomplished by Dewey nothing special but only the renewal of a motif of the empiricist tradition? That would be the case if Dewey agreed with the empiricist notion of science. On the contrary, however, Dewey is quite explicit in his rejection of it:

it should be noted that traditional empiricism has also misread the significance of conceptions or general ideas. It has steadily opposed the doctrine of their a priori character; it has connected them with experience of the actual world. But even more obviously than the rationalism it has opposed, empiricism has connected the origin, content and measure of validity of general ideas with antecedent existence. According to it, concepts are formed by comparing particular objects, already perceived, with one another, and then eliminating the elements in which they disagree and retaining that which they have in common. Concepts are thus simply memoranda of identical features in objects already perceived; they are conveniences, bunching together a variety of things scattered about in concrete experience. But they have to be proved by agreement with the material of particular antecedent experiences; their value and function is essentially retrospective. Such ideas are dead, incapable of performing a regulative office in new situations. They are "empirical" in the sense in which the term is opposed to scientific--that is, they are mere summaries of results obtained under more or less accidental circumstances. (LW 4: 132-133) 
What is significant in this passage from The Quest for Certainty is not only the fact that it dismisses the empiricist idea of science, but also that it culminates in an emphasis on "the active and productive character of ideas, of thought" (LW 4: 133). The novelty of Dewey in comparison with the conflicting options of modern philosophy is in his experimental idealism and its reuniting of experience and "reason." Accordingly, in the context of the present discussion focused on the binomial/ dichotomy science-childhood (within a more general question about what it means to educate thinking), it is much more promising to consider Dewey's step forward with regard to modern rationalism. In other words, if the major Deweyan innovation is the thought-ful child (to say it in the form of a pun), it is better to investigate it against the backdrop of Dewey's break with the modern rationalist tradition.

It is necessary to understand well the radical overthrow that Dewey accomplishes. It is a commonplace to say that Dewey discovers children as inquirers; more radically, he can attribute an epistemic activity to children to the extent that he thinks of science as inquiry and in the same move (parallel and diametrically opposite to Descartes's pattern) he can think of science as inquiry because he takes leave from modern rationalism, that is, from that ostracism of our primordial experience of the world which takes place eminently in childhood but more generally belongs to us as beings-in-the-world and subjects having experiences.

In Dewey's works there is a significant textual clue which signals how in the redefinition of the relationships between science and children's knowledge it is the reinterpretation of modernity that is at stake. This clue is the metaphor of the Copernican revolution, which Kant introduces in the preface to the second edition of the Critique of the Pure Reason and which may be the most important "figure" of modern philosophy along with the Cartesian cogito. In Dewey, the metaphor appears in two strategic moments of his production, chronologically distant from each other but-for the reasons I am attempting to illustrate-intimately connected with each other. First, the use of the Copernican revolution theme occurs in School and Society, the text through which Dewey ushers pedagogy into the XX century: "Now the change which is coming into our education is the shifting of the centre of gravity. It is a change, a revolution, not unlike that introduced by Copernicus when the astronomical centre shifted from the earth to the sun. In this case the child becomes the sun about which the appliances of education revolve; he is the centre about which they are organized" (MW 1:23).

As is well known, in Kant the Copernican revolution refers to the overthrowing of the classical view of the relationship between the knowing subject and things. Instead of asking how things are in themselves, we have to ask how they have to be in order to be known by us (Kant, 1998, p. 25). Intertextuality, therefore, links the passage from School and Society, which at first sight could appear to be typically pedagogical, with an "epistemological" constellation: what is at stake is a transition to a new mode of understanding knowledge. However, such a transition is not construed in Kantian terms but instead takes leave of Kant, to the extent that the 
latter had ended up confirming the classical view revolving around the spectator theory of knowing. The Quest for Certainty culminates, in fact, in the Copernican revolution, and the latter is explicitly spelled out in contrast with Kant (LW 4: 229). In line with his overcoming of Cartesian adamitic science, Dewey argues that

[t]he meaning of a Copernican reversal is that we do not have to go to knowledge to obtain an exclusive hold on reality. The world as we experience it is a real world. But it is not in its primary phases a world that is known, a world that is understood, and is intellectually coherent and secure. Knowing consists of operations that give experienced objects a form in which the relations, upon which the onward course of events depends, are securely experienced.... The knower is within the world of existence; his knowing, as experimental, marks an interaction of one existence with other existences. ... Knowledge then does not encompass the world as a whole. But the fact that it is not coextensive with experienced existence is no defect nor failure on its part. It is an expression of the fact that knowledge attends strictly to its own business:- transformation of disturbed and unsettled situations into those more controlled and more significant.

(LW 4: 229)

By weaving together the different threads here, we can say that there is a selffueling circularity between the shift in the educational center of gravity and the change in the way of understanding knowledge and its relationship with (the world of) experience. It is because we abandon the spectator model of knowing that we can recognize the child as a pivot of the educational process and, in turn, the recognition of the child's centrality sheds light upon the significance of a really accomplished Copernican revolution and of a "non-Cartesian" modernity.

From this perspective, careful scrutiny of the different roles played by education in Descartes and Dewey will help us to move a step forward in the argumentation. In his Regulae ad directionem ingenii (1628), Descartes explains how education is a good thing in order to prevent young men, who do not have the whole use of reason, from making errors (Descartes, 1908, p. 364). But when the mind matures, men can and must give up every educational relationship and find by themselves the rules by means of which they can attain real knowledge (p. 364). Therefore, for Descartes education is not related to the flourishing of thinking, it is just a provisional device before the mind develops (and-nota bene-the mind develops independently of the process of education). The mind is not to be educated, it just matures and becomes able to recognize the rules of the method. Education is not a road to science but only a strategy of containment before the cogito installs itself and enables us to arrive at science as absolutely certain knowledge.

Cartesian modernity orchestrates, therefore, the idea of the "unfolding of latent powers from within" (MW 9: 82) - that is, the cogito is the outcome of a process of maturation-and of the "formation from without" (MW 9: 82)-that is, the school as a containment agency informs, not only in the sense of providing 
youth with notions but, more radically, in giving them form, shape, so avoiding their dissipation and their going astray. Consequently, Cartesian modernity is not able to think of education as the "reconstruction or reorganization of experience which adds to the meaning of experience, and which increases ability to direct the course of subsequent experience" (MW 9: 82). Cartesian reason is something remote from experience and, more generally, Cartesian subjectivity constitutes itself by establishing the citadel of the cogito and by distancing itself from transaction with the environment.

On the contrary, Deweyan subjectivity-as-experience-of-the-world demands education as the indispensable condition of its growth. And, insofar as it is linked with and rooted in experience, Deweyan "thinking" is not a pure faculty, "purified" - through the evil genius-from the interlacement with existence. Rather, it is intelligence, the name of "reason" to the extent that it has incorporated the experimentalism of modern science and is employed to enrich and expand experience: "Intelligence is not something possessed once for all. It is in constant process of forming, and its retention requires constant alertness in observing consequences, an open-minded will to learn and courage in re-adjustment" (MW 12: 135).

All this implies two things: first, education (of "reason" as intelligence) is possible only within a Deweyan framework, one that infringes on Descartes's separation of reason and education by recognizing the experimental character of thinking; second, only in a Deweyan framework does school stop being a containment device and really become an educational agency. And this happens only to the extent that in school there is "a counterpart" to "that freed activity of mind which we term 'science"' (MW 3:236). Inquiring should, then, take the place of acquiring (MW 3:236) and school should become the privileged context for the cultivation of intelligence.

The switch from (Cartesian-Kantian) reason to intelligence, the interpretation of science as inquiry, and the idea of children as inquiring and animated by the same attitude as the scientific mind are inextricably linked with one another and constitute an essential part of the Deweyan road to "[t]he genuinely modern [that] has still to be brought into existence" (MW 12: 273), that is, to a non-Kantian Enlightenment.

Indeed, on the one hand it is impossible to underrate the importance of Kant in the recognition of the "universality" of reason and its move away from the aristocratic differentiations obtaining in the metaphysical tradition. In his first Critique, Kant is quite clear on this and speaks of "an universal human reason, in which each and everyone has his own voice" (1998, p. 640). But this universal recognition excludes children and their epistemic rights (and-for the set of relationships I have tried to spell out-this is further evidence of how the scientific attitude in Kant receives a nonexperimental treatment). In his epoch-making $A n$ swer to the Question: “What is Enlightenment?", Kant defines Enlightenment as "man's emergence from his self-incurred immaturity. Immaturity is the inability to use one's own understanding without the guidance of another" (1998, p. 53). 
Immaturity is Unmündigkeit, in which the word Mund (mouth) resonates: Unmündigkeit can, then, be construed as in-fantia, infancy. Children are the in-fants, those who are not able to have a voice in universal human reason-and accordingly education is Zucht, discipline, and Unterweisung, instruction, before being Bildung, human education.

Although Dewey does not fully grasp the connection between Kantian immaturity and a specific idea of childhood knowledge and of education, he is well aware of the undemocratic implications of the Kantian version of Enlightenment (MW 8: 156-157). The Deweyan idea of democracy in education stands in opposition to such a theoretical framework; it appeals to a replacement of the "external authority of action" by the "internal authority of truth, discovered and known to reason" (MW 3: 229) and invokes a "[r]eform of education in the direction of greater play for the individuality of the child [that] means the securing of conditions which will give outlet, and hence direction, to a growing intelligence" (MW 3: 235). That is attained, as already mentioned, by making school attuned to the intellectual revolution represented by modern science, with its intertwining of firsthand experience and reflective thinking. Dewey's accomplished Enlightenment does, then, include the growing intelligence of children, their voice in universal reason, and therefore their intellectual freedom as opposed to the subjection of the mind "to an outside and ready-made material" (MW 3: 235).

Dewey is explicit in rejecting the Romantic interpretation of childhood freedom and in connecting it to the scientific mentality:

Misunderstanding regarding the nature of the freedom that is demanded for the child is so common that it may be necessary to emphasize the fact that it is primarily intellectual freedom, free play of mental attitude, and operation which are sought. If individuality were simply a matter of feelings, impulses, and outward acts independent of intelligence, it would be more than a dubious matter to urge a greater degree of freedom for the child in the school. (MW 3: 235)

But why did Dewey not think of the cultivation of such an intellectual freedom (also) through philosophy? Why did he not mobilise philosophical inquiry as an educational strategy? The question concerns Dewey's blindness to the educational potential of philosophy, even given his significant insight into the inquiring powers of children. And the issue is the more urgent in consideration of what Dewey means by "philosophy": it is traced back to "the original and etymological sense of the word ... philosophy is a form of desire, of effort at action-a love, namely, of wisdom; but with the thorough proviso, not attached to the Platonic use of the word, that wisdom, whatever it is, is not a mode of science or knowledge" (MW 11: 43; see also LW 16: 319, 376). If philosophy is a love of wisdom and not a mode of science, does the Deweyan scotomization of the educational function of philosophy entail a rejection of the possibility that children can be in search of wisdom? Is the "Deweyan" child only a scientific inquirer but not a philosopher? In a way, does 


\section{Stefano Oliverio}

Dewey repropose the traditional separation of childhood knowledge and philosophy, despite his emphasis on the intellectual potential of children?

The conclusion cannot be so drastic as it would presuppose an unbridgeable gap between science and philosophy (such as, for instance, there is in neopositivism). Whereas, for Dewey, although philosophy is not a mode of science, it is not separated from science, it is not the "mere arbitrary expression of wish or feeling or a vague suspiration after something, nobody knows what" (MW 11: 46), and nothing that is not consistent with the most advanced science can be hosted in "any sincere philosophizing" (LW 3: 9). Once again: if this link obtains, and if the inquiring powers of children are stressed, why not take into account the possibility of children doing philosophical inquiry?

There are many ways of tackling such an enigma, but here I will confine myself to speculating on some possible reasons why for Dewey philosophy cannot be an activity suitable for children. First, although no philosophical thinking can be divorced from a historical and geographical context, under penalty of becoming "a beating of wings in the void" (LW 6: 21), philosophical thinking "is, upon the whole, at the extreme end of the scale of distance from the active urgency of concrete situations" (LW 6: 17) and accordingly could have appeared to Dewey less appropriate for children's education, which should be rooted in their world of life and in firsthand experience. Indeed, the study of philosophy would require in an eminent way that voluntary attention which Dewey fully recognizes only when

the child entertains results in the form of problems or questions, the solution of which he is to seek for himself. In the intervening stage (in the child from eight to, say, eleven or twelve), while the child directs a series of intervening activities on the basis of some end he wishes to reach, this end is something to be done or made, or some tangible result to be reached; the problem is a practical difficulty, rather than an intellectual question. But with growing power, the child can conceive of the end as something to be found out, discovered, and can control his acts and images so as to help in the inquiry and solution. This is reflective attention proper. (MW 4: 201-202)

The very possibility of a "Philosophy for Children" stricto sensu would be excluded, then, first of all for psychological reasons.

Second, philosophy is an "imaginative formulation" and a "conversion of [a] culture as [it] exists into consciousness" (LW 3: 9), and it is "criticism of the influential beliefs that underlie culture; a criticism which traces the beliefs to their generating conditions as far as may be, which tracks them to their results, which considers the mutual compatibility of the elements of the total structure of beliefs. Such an examination terminates, whether so intended or not, in a projection of them into a new perspective which leads to new surveys of possibilities" (LW 6: 19). Furthermore, philosophy has the task of connecting the different areas of a culture. In the memorable words of the final chapter of Experience and Nature, "[o]ver-speciali- 
zation and division of interests, occupations and goods create the need for a generalized medium of intercommunication, of mutual criticism through all-around translation from one separated region of experience into another. Thus philosophy as a critical organ becomes in effect a messenger, a liaison officer, making reciprocally intelligible voices speaking provincial tongues, and thereby enlarging as well as rectifying the meanings with which they are charged" (LW 1:306).

As such, philosophy could be interpreted as demanding preliminarily a familiarization with one's culture, which would constitute the first step of any education. This does not mean that such a familiarization should be acritical: it would be inspired by an inquiring spirit. However, philosophy would be a sort of meta-level criticism that could occur only after a prior in-habitation (in a quite literal sense of the acquisition of habits) of one's culture, carried out through an immersion in the world of social practices.

Third, philosophy has mainly flourished in "times of great stress and strain in human affairs" (LW 16: 360), in "a general state of uneasiness due to the danger of disintegration within the established order" (LW 16: 359), when there is the pressing need to mediate between "conflicting authorities" (LW 4: ch. 3; MW 12), when the task of the reconstruction of culture is particularly urgent because the rift between the old system of beliefs and new contexts/environments/emergences is in danger of becoming fatal. Now, although Dewey valorizes their intellectual freedom, children are to him principally the locus of the impulse as "a pivot of readjustment, re-organization, in habits" (MW 14: 75), they represent the irruption of the new that can prevent habits from being encrusted. In this sense, more than philosophy for children (that is, philosophy as a practice done by children) what could interest Dewey is a philosophical stance on the part of adults in the education of children which would prevent the natural "combat" (MW 14: 71) between habits and impulses from becoming a calamitous warfare-that is something that blocks growth both at the individual and at the social level. In other words, if the task of philosophy is that of mediating between the old and the new, it seems to be Dewey's strategy to emphasize the role that philosophy could have for adults (as the embodiment of the old) in their encounter with the new (as the appeal to readjustment) rather than the part it can play for children (as the embodiment of the new) in their dialogue with the established values and in what I have called the-critical-familiarization with one's culture.

All these answers can also be summarized-with a certain grain of hermeneutical violence-by saying that what prevents Dewey from mobilizing philosophy in education is the "permanent Hegelian deposit" (LW 5: 154) in him. That would be the deep root of the scotoma I am here speculating on, that is, of his blindness to the educational value of philosophy "going to school" in Lipman's (1988) sense that the philosophical tradition can be put to work in the classroom as a tool for educating thinking through philosophical inquiry. And it would be a theoretical root that results in a methodological impasse (exactly that impasse which Lipman 


\section{Stefano Oliverio}

will go through by inventing his curriculum and devising the model of the community of philosophical inquiry). It is surely possible to detect in Dewey's works passages that suggest the notion of philosophizing as a form of careful (but not specialized) reflection, which in this sense is accessible to children, for the aforementioned reasons. But it is not only such a way of interpreting philosophy which Lipman is interested in. Lipman intends to mobilize the very tradition of philosophy, that repertoire of ideas, concepts, and so on, which constitute a major heritage of our civilization. And it is here that Lipman parts company with Dewey. The latter maintains a Hegelian approach towards such a heritage, which emerges for instance at the very beginning of Experience and Nature:

It does not follow that the products of these philosophies which have taken the wrong, because non-empirical, method are of no value or little worth for a philosophy that pursues a strictly empirical method. The contrary is the case, for no philosopher can get away from experience even if he wants to. The most fantastic views ever entertained by superstitious people had some basis in experienced fact; they can be explained by one who knows enough about them and about the conditions under which they were formed. And philosophers have been not more but less superstitious than their fellows; they have been, as a class, unusually reflective and inquiring. If some of their products have been fantasies, it was not because they did not, even unwittingly, start from empirical method; it was not wholly because they substituted unchecked imagination for thought. No, the trouble has been that they have failed to note the empirical needs that generate their problems, and have failed to return the refined products back to the context of actual experience, there to receive their check, inherit their full content of meaning, and give illumination and guidance in the immediate perplexities which originally occasioned reflection. [There is] no pretence, accordingly, of starting to philosophize afresh as if there were no philosophies already in existence, or as if their conclusions were empirically worthless. Rather the subsequent discussions rely, perhaps excessively so, upon the main results of great philosophic systems, endeavoring to point out their elements of strength and of weakness when their conclusions are employed (as the refined objects of all reflection must be employed) as guides back to the subject-matter of crude, everyday experience. (LW 1:36-37)

First of all, it is noteworthy how Dewey links the enduring fruitfulness of past philosophies-even the nonempirical ones-with the possible connections that can be established with the level of everyday experience. In a sense, this is exactly what Lipman realized 50 years later in creating his curriculum. Indeed, in writing his stories Lipman moves from some ideas (e.g., beauty, justice) and from the treatment they received in the philosophical tradition; he then identifies experiential situations-suitable for children-in which those ideas can operate as possible tools to reconstruct and reorganize experience in order to add to meaning; finally, he embodies the different epistemic options (corresponding to different 
philosophical traditions) in different characters, characters who are engaged in a common inquiry, homologous to and modeling the inquiry which will take place in the classroom community of inquiry.

From this perspective, such a move is typically Deweyan in that Lipman reconnects past philosophies to the level of experience and, by doing so, rediscovers their permanent value. But Lipman and Dewey part company because in Lipman there is a "dramatization" of philosophy by "casting it in the modality of fictional narrative" (Lipman, 1995-1996, p. 64) and of exercises and discussion plans. In particular,

both exercises and discussion plans are embodiments of certain aspects of philosophical praxis, with exercises focusing on individual problems and cases and with discussion plans centering on general or universal concepts. Both are representative of the philosophical tradition, as embodied in the theories of the discipline or in its practice. At the same time, both provide opportunities for going beyond that tradition, as philosophers have always managed to go beyond it. These modes of transcending the tradition are as authentically a part of the tradition as are the modes of conforming to the tradition. To do philosophy is to belong to a community whose members teach one another to do both. Doing philosophy also involves recognizing and respecting those whose openness of mind and freshness of thought enables them to be philosophically creative without prior instruction in how this might be helped to happen. Those who refuse to acknowledge the philosophical originality of a thinker simply because that thinker happens to be a child are guilty of the fallacy that is awkwardly called "ad hominem." (Lipman, 1995-1996, p. 64)

Lipman explicitly intertwines the original (Socratic) view of philosophy with the activist stance in pedagogy:

Either way, philosophical inquiry is student-centered, and it is the thinking of each student that is dramatized, as well as the thinking of each collective group. The philosophical admonition to "Know Thyself" is not to be taken lightly, nor is the Socratic warning that "The unexamined life is not worth living." It is the life of each and every philosophy student that must be examined and understood. Each student's mind becomes a theatre within a theatre, a drama within a drama. (Lipman, 1995-1996, p. 77)

When Dewey emphasizes the permanent value of (the history of) philosophy, there is, on the contrary, a sort of Hegelian Er-innerung (the recollecting interiorization of the history of philosophy) turned into a form of experimental inquiry (that is, construed in the vocabulary of naturalistic humanism). Like Hegel in the Phenomenology of Spirit, Dewey in Experience and Nature retraces some of the main "figures" of the development of the philosophical thought but he does not consider them as steps in a unique unfolding history, finally reappropriated by the philosopher as the "organ" of the absolute spirit; rather, he takes them as theoretical options which can still be viable for the reorganization of experience, provided 
that they are connected with the constantly new emergences of culture. In other words, in Dewey the philosophical tradition seems to reacquire value (exclusively) in this highly sophisticated work of reappropriation and recontextualization, work which is obviously beyond children's power.

Such a Hegelian background in assessing the value of the philosophical tradition seems to bar Dewey's chance of seeing other forms of its mobilization. Lipman's major move (the creation of the curriculum and the invention of the community of philosophical inquiry as an educational setting) is not only, therefore, a methodological move, it also has conspicuously theoretical implications: it takes leave of a substantially Hegelian approach to the history of philosophy and explores the possibility of reterritorializing it into childhood experience. Lipman would agree with Dewey's assertion that "[t]here is a special service which the study of philosophy may render. Empirically pursued it will not be a study of philosophy but a study, by means of philosophy, of life-experience" (LW 1: 40). In Dewey, philosophy as a "critique of prejudices," as a reflection on "experience [that] is already overlaid and saturated with the products of the reflection of past generations and by-gone ages [and] filled with interpretations, classifications, due to sophisticated thought, which have become incorporated into what seems to be fresh naïve empirical material" (LW 1: 40), seems to belong only to the philosopher as a cultural critic; on the contrary, Lipman believes in the possibility of translating it into stories, exercises, and discussion plans, an activity that can allow children to start an inquiry and make sense of their world and their experience.

Such a work of reterritorialization was at the same time the espousing of the Socratic doing philosophy (Lipman, 1991, p. 12) and the Deweyan learning by doing. From this wedding the child as a philosopher was born.

\section{Note}

1. In reality, Adam, as the symbol of absolutely perfect rational faculties, reappears also in the Enquiry Concerning Human Understanding as a sort of thought experiment aimed at showing how there is no a priori knowledge of the causal connection.

\section{References}

Citations of the works of John Dewey refer to the critical edition published by Southern Illinois University Press. Volume and page numbers follow the initials of the series. Abbreviations for the critical edition are:

$\begin{array}{ll}\text { EW } & \text { The Early Works (1882-1898). } \\ \text { MW } & \text { The Middle Works (1899-1924). } \\ \text { LW } & \text { The Later Works (1925-1953). }\end{array}$

Arendt, H. (1982). Lectures on Kant's Political Philosophy. Chicago: University of Chicago Press. 
Descartes, R. (1908). Regulae ad directionem ingenii. In Oeuvres de Descartes (Vol. 10). Paris: Léopold Cerf. (Original work published 1628).

_- - Principia philosophiae. In Oeuvres de Descartes (Vol. 8). Paris: Léopold Cerf, 1908. (Original work published 1644).

Hume, D. (1740). An Abstract of A Treatise of Human Nature. Retrieved November 26, 2011, from http://www.class.uidaho.edu/mickelsen/texts/Hume\%20\%20 -\%20Abstract.htm.

Kant, I. (1998). Beantwortung der Frage: Was ist Aufklärung? In Werke, vol. 6. Schriften zur Anthropologie, Geschichtsphilosophie, Politik und Pädagogik. Darmstadt: Wissenschaftliche Buchgesellschaft. (Original work published 1784).

- - - (1998). Kritik der reinen Vernunft. In Werke (Vol. 2). Darmstadt:

Wissenschaftliche Buchgesellschaft. (Original work published 1787).

Kennedy, D. (1989). "Fools, Young Children, Animism, and the Scientific World-

Picture." Philosophy Today, 23(4).

Lipman, M. (1988). Philosophy Goes to School, Philadelphia: Temple University Press. -_- . (1991). Thinking in Education. Cambridge: Cambridge University Press.

-_- (1995-1996). "Philosophical Discussion Plans and Exercises." Analytic Teaching, 16(2), 64-77.

- - - (2003). Thinking in Education (2 $2^{\text {nd. }}$ ed). Cambridge: Cambridge University Press.

Lipman, M., \& Sharp, A. M. Growing up with Philosophy. Dubuque, IA: Kendall/ Hunt Publishing.

Nussbaum, M. C. (2010). Not for Profit. Why Democracies Need the Humanities. Princeton: Princeton University Press.

Oliverio, S. (2011). “'Outfoxing nature': Matthew Lipman and the Prolegomena to a Pedagogy of Science." Childhood and Philosophy, 7(13), 141-160.

Robison, W. L. (2006). “Hume's Other Writings.” In S. Traiger (Ed.), The Blackwell Guide to Hume's Treatise. Oxford: Blackwell.

Sharp, A. M., \& Reed, R. F. (Eds.). (1992). Studies in Philosophy for Children. Harry Stottlemeier's Discovery. Philadelphia: Temple University Press.

Striano, M. (2002). "La filosofia come educazione del pensiero. Una conversazione pedagogica con Matthew Lipman.” In A. Cosentino, Filosofia e formazione. 10 anni di Philosophy for Children in Italia (1991-2001). Napoli: Liguori.

Taylor, C. (2007). A Secular Age, Cambridge: Belknap Press.

Stefano Oliverio teaches at theUniversity of Naples Federico II.

E-mail:stefano.oliverio@unina.it 